\title{
Prevalence of Spinal Metastasis in Neurosurgical Procedures: A Descriptive Study
}

\author{
Jefferson Walter Daniel*, José Carlos Esteves Veiga \\ Division of Neurosurgery, Santa Casa de São Paulo-School of Medical Sciences, São Paulo, Brazil \\ Email: *jefferson.w.daniel@gmail.com, jcemveiga@uol.com.br
}

How to cite this paper: Daniel, J.W. and Veiga J.C.E. (2016) Prevalence of Spinal Metastasis in Neurosurgical Procedures: A Descriptive Study. Open Journal of Epidemiology, 6, 191-197.

http://dx.doi.org/10.4236/ojepi.2016.64021

Received: August 25, 2016

Accepted: November 5, 2016

Published: November 8, 2016

Copyright $\odot 2016$ by authors and Scientific Research Publishing Inc. This work is licensed under the Creative Commons Attribution International License (CC BY 4.0).

http://creativecommons.org/licenses/by/4.0/

\section{Abstract}

Objective: This study sought to identify the prevalence of operations for spinal epidural neoplastic metastases relative to other spine and neurosurgical operative procedures. Methods: This study was descriptive and involved a retrospective review of data collected from patients who underwent neurosurgeries between February 1997 and January 2015 at a single quaternary hospital. The examined population was distributed across five descriptive categories to perform numerical distributions among neurosurgical operative procedures. Results: A total of 12,802 neurosurgical procedures were identified. These procedures were classified as follows: Skull and brain, 11,192 (87.42\%); spinal column and spinal nervous tissue, 1462 (11.42\%); and peripheral nerves, 148 (1.16\%). Surgical procedures for the 1462 (100\%) cases of spinal column and spinal nervous tissue diseases were distributed by nosology as follows: Degenerative intervertebral disk and spondylosis, 768 (52.54\%); neoplastic, 279 (19.08\%); traumatic, 221 (15.11\%); congenital, 163 (11.14\%); infectious and inflammatory, 27 (1.85\%); and vascular, $4(0.28 \%)$. With respect to the distribution of the 279 (100\%) surgical procedures for spinal column and spinal nervous tissue neoplastic diseases, 124 (44.44\%) procedures were for intradural neoplasms, and 155 (55.56\%) procedures were for epidural spinal column neoplasms. The 155 (100\%) operations for epidural neoplastic diseases were distributed into two groups: Primary epidural neoplasms, 42 (27.10\%); and secondary epidural neoplasms, 113 (72.90\%). Spinal column epidural neoplastic metastases (secondary neoplasms) represented $0.88 \%$ of the 12,802 neurosurgical procedures. Conclusions: Surgical procedures for spinal metastasis are uncommon with respect to all neurosurgical operative procedures. Trend analysis reveals an unchanging trend of prevalence for these procedures.

\section{Keywords}

Epidemiology, Neoplasm Metastasis, Neurosurgical Procedures, Prevalence, Spine 


\section{Introduction}

The vertebral column is the most common site of skeletal metastases and is involved in approximately $40 \%$ of cancer-related deaths [1] [2] [3] [4]. Spinal epidural neoplastic metastases as the initial clinical manifestation of cancer comprise $20 \%$ of all new diagnoses of spinal epidural metastases [5] [6], and the cumulative probability of spinal cord compression caused by malignant disease in the 5 years preceding death from cancer is 2.5\% [6] [7]. The site of origin of a histologically documented carcinoma is not identified clinically in approximately $3 \%$ of patients [8]. Surgical treatment is required in $5 \%-10 \%$ of patients [9], and a 3-month post-operative survival period justifies surgical treatment of patients for spinal epidural neoplastic metastasis [10] [11].

In 2014, the estimated incidence of new primary cancers in Brazil was 576,000 (2.84\%) [12] among a total population of 202,768,662 [13]. No official government statistics exist regarding the prevalence of spinal metastases among cancer patients [12]. Knowledge of the descriptive prevalence of surgical operative procedures in patients who harbour spinal epidural neoplastic metastases remains lacking in the Brazilian medical literature, and this information could supplement the lack of epidemiological cancer data.

Reporting the prevalence of a specific disease among a population at a given point provides an accurate measurement of the studied problem [14]. Accurate cancer measurements improve population health by collective actions in public health policies [15]. The purpose of this study is the characterization of neurosurgical operative procedures into descriptive categories, which perhaps can indicate trends and patterns in spinal epidural neoplastic metastasis for future cancer research.

The objective of this study is to generate descriptive numerical distributions among patients undergoing operations for spinal epidural neoplastic metastases with respect to neurosurgical operative procedures and other surgically treated spinal column and spinal nervous tissue diseases.

\section{Methods}

The study design was observational and descriptive. This research involved a retrospective review of data collected from the electronic archives of patients who underwent neurosurgeries in the Division of Neurosurgery of a single quaternary hospital between February 1997 and January 2015. The primary author collected the study data from the registry files of the hospital's neurosurgical division.

Surgical demographic data were collected using the direct method of census, i.e., the performed neurosurgeries were counted. The prevalence of spinal metastases was compared with those of other surgical spinal column and spinal nervous tissue diseases. Trend analysis was applied to determine the yearly pattern of prevalence (whether the trend was increasing, decreasing or unchanging) of surgical procedures for spinal metastases relative to the total number of neurosurgeries. Individual patient demographics and clinical characterizations were neither collected nor analysed. Magnetic resonance and computerized tomography spinal imaging were used to locate neoplasms in the vertebrae and indicate their relationship to the thecal sac. Pathologists from the institution's 
pathology department reviewed the post-operative histological diagnoses of tumours. All patients in this study received treatment at no cost to them.

In the conceptual framework for the studied population, the research data were organized into the following five descriptive categories for numerical comparisons:

1. Neurosurgical procedures with respect to anatomical regions.

2. Spinal column and spinal nervous tissue disease patients classified by nosology as follows: degenerative intervertebral disk and spondylosis; neoplastic; traumatic; congenital; infectious/inflammatory; and vascular.

3. Spinal column neoplasms classified as intradural and epidural with respect to their thecal sac anatomical localization. All histological cancer types were included in the intradural anatomical classification system, and intramedullary and extramedullary diseases were not distinguished.

4. Spinal column epidural neoplasms classified into primary and secondary tumours based on their biological aetiology. Primary epidural neoplasms originated from the vertebrae, and secondary (metastatic) epidural tumours were transmitted from a distant primary tumour via a haematogenous route, direct neighbour-organ extension, or intradural cerebrospinal fluid-brain drop metastasis.

5. Neurosurgical procedures and secondary (metastatic) epidural spinal column neoplasms.

The research project was approved on January 27, 2016 by the Ethics Committee on Human Research in the Faculdade de Ciências Médicas da Santa Casa de Misericórdia de São Paulo (protocol number 1.396.194, cepsc@santacasasp.org.br; National Research Registry Number 52519116.2.0000.5479, http://aplicacao.saude.gov.br/). Patient identities were not accessed, and informed oral consent was exempted. The ethics conformed to the standards of the Declaration of Helsinki of 1975, as revised in 2000.

Statistical analyses were limited to quantitatively describing the primary features of the collected information, expressed by frequency, and the interval estimate of the sample, expressed by the confidence interval. Trend analysis was utilized to estimate the surgical prevalence of spinal metastases. IBM Statistical Package for the Social Sciences (SPSS, Inc., Chicago, IL, USA), version 13.0, was used for the statistical analysis.

\section{Results}

Censuses included 12,802 (100\%) neurosurgeries performed during the 19-year study period. Surgical demographic data were distributed into five descriptive categories.

1. Neurosurgical procedures, $12,802(100 \%)$, distributed as follows with respect to anatomical regions (Table 1 ).

2. Spinal column and spinal nervous tissue disease, 1462 (100\%), classified based on nosology as follows (Table 2).

3. Spinal column neoplasms, $279(100 \%)$, distributed as follows relative to their thecal sac anatomical localization (Table 3 ).

4. Spinal column epidural neoplasms, 155 (100\%), categorized into primary and secondary tumours as follows based on their biological aetiology (Table 4). 
5. Neurosurgical procedures relative to secondary (metastatic) epidural spinal column neoplasms: Spinal column epidural neoplastic metastases were involved in $0.88 \%$ of the 12,802 neurosurgical procedures (Table 5).

Table 1. Distribution of neurosurgical procedures with respect to anatomical region between February 1997 and January 2015.

\begin{tabular}{cccc}
\hline Anatomical Location & \# Neurosurgeries & Percentage & 95\% CI \\
\hline Skull and brain & 11,192 & $87.42 \%$ & $16.85-88.00$ \\
Spinal column and spinal nervous tissue & 1462 & $11.42 \%$ & $10.87-11.97$ \\
Peripheral nerves & 148 & $1.16 \%$ & $0.971-1.34$ \\
Total & 12,802 & $100 \%$ & \\
\hline
\end{tabular}

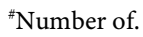

Table 2. Distribution of spinal column and spinal nervous tissue disease patients subjected to surgery with respect to nosology between February 1997 and January 2015.

\begin{tabular}{cccc}
\hline Nosology & ${ }^{*}$ Spine surgeries & Percentage & $95 \%$ CI \\
\hline Degenerative intervertebral disk and spondylosis & 768 & $52.54 \%$ & $49.98-55.10$ \\
Neoplastic & 279 & $19.08 \%$ & $17.07-21.09$ \\
Traumatic & 221 & $15.11 \%$ & $13.27-16.94$ \\
Congenital & 163 & $11.14 \%$ & $9.57-12.75$ \\
Infectious and inflammatory & 27 & $1.85 \%$ & $1.15-2.54$ \\
$*$ Vascular & 4 & $0.28 \%$ & $0-0.6$ \\
Total & 1462 & $100 \%$ & \\
\hline
\end{tabular}

${ }^{*}$ Number of; ${ }^{*}$ Vascular spinal column and spinal nervous ailments were almost exclusively treated using percutaneous endovascular procedures.

Table 3. Distribution of intradural and epidural spinal column neoplasms between February 1997 and January 2015.

\begin{tabular}{cccc}
\hline Anatomical distribution & "Spine surgeries & Percentage & $95 \%$ CI \\
\hline Intradural neoplasms & 124 & $44.44 \%$ & $38.61-50.27$ \\
Epidural neoplasms & 155 & $55.56 \%$ & $49.73-61.39$ \\
Total & 279 & $100 \%$ & \\
\hline
\end{tabular}

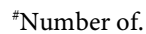

Table 4. Classification of primary and secondary epidural spinal column neoplasms between February 1997 and January 2015.

\begin{tabular}{cccc}
\hline Biologic tumour aetiology & ${ }^{*}$ Spine surgeries & Percentage & $95 \%$ CI \\
\hline Primary epidural neoplasms & 42 & $27.10 \%$ & $20.10-39.09$ \\
Secondary epidural neoplasms & 113 & $72.90 \%$ & $65.91-79.90$ \\
Total epidural neoplasms & 155 & $100 \%$ & \\
\hline
\end{tabular}

"Number of. 
Table 5. Distribution of the neurosurgical procedures and secondary (metastatic) epidural spinal column neoplasms between February 1997 and January 2015.

\begin{tabular}{ccc}
\hline Types of surgeries & "Surgeries & Percentage \\
\hline Neurosurgeries & 12,802 & $100 \%$ \\
Spinal secondary epidural neoplasms & 113 & $0.88 \%$ \\
\hline
\end{tabular}

"Number of.

Trend analysis revealed an unchanging trend (event rate, $0.88 \% /$ year) for $113(0.88 \%)$ surgical procedures in spinal metastases relative to the total of $12,802(100 \%)$ neurosurgeries between February 1997 and January 2015.

\section{Discussion}

The purpose of this study was to determine the prevalence of surgical patients who harbour spinal epidural neoplastic metastasis, apply the findings to cancer epidemiology research, and foresee trends and patterns of this disease in defined populations. These data contribute to public health policies, evidence-based practice, and neurosurgical demographic data.

This study differs from the published literature due to the numerical descriptive comparisons among neurosurgical procedures with a focus on patients undergoing operations for spinal column epidural neoplastic metastasis.

The overall descriptive census of neurosurgical procedures is not commonly revealed by single neurosurgical divisions. A paucity of information exists concerning the neurosurgical demographic prevalence among surgical patients treated for spinal epidural neoplastic metastasis with respect to all neurosurgical operative procedures. This descriptive result is not available among the accessed literature.

In 1982, Perrin et al. [16] reported the presence of 11 (5.5\%) intradural spinal column metastases among 200 symptomatic epidural spinal metastases. In 2013, Daniel [17] characterized 212 (100\%) surgical cases of epidural and intradural spinal column tumours over a 14-year time span. Among these 212 cases, 110 (51.89\%) and 102 (48.11\%) cases involved epidural and intradural tumours (including all histological types), respectively. Of the 110 (100\%) epidural spinal column tumours, 74 (67.27\%) were secondary (metastasis), and 36 (32.73\%) were primary tumours (localized in vertebrae).

The obtained descriptive results in this study indicate that surgical operative procedures for spinal metastases are uncommon. Trend analysis also indicates an unchanged annual trend of surgical prevalence for these procedures during the study period. Surgical cases of spinal column epidural neoplastic metastases represented $0.88 \%$ of the 12,802 neurosurgical procedures. However, relative to the $1462(100 \%)$ total spinal column and spinal nervous tissue surgeries, the 113 (7.72\%) operative procedures for spinal metastases seemed common. The reason for this discrepancy is that in our neurosurgical division, the demand for neurosurgical operative procedures for ailments of the central nervous system is greater than that for spinal column ailments. This finding may represent an epidemiological regional characteristic for high-volume quaternary 
care centres including teaching hospitals.

This study's limitation lies in its conceptual framework. Descriptive research is limited to descriptions of past facts of a population's characteristics and precedes the hypotheses of exploratory research. Knowledge of past facts allows researchers to structure the scientific questions prompting hypotheses. Thus, descriptive studies in observational epidemiology do not explain causal relationships. Internal validity is a less important scientific requirement. No attempt was made to explore the causes underlying the obtained numerical frequency results. Future studies will be performed to identify the epidemiological reasons underlying the observed unchanging trend of prevalence for spinal metastasis surgeries at our health institution.

\section{Conclusion}

Surgical procedures for spinal metastasis are uncommon with respect to all neurosurgical operative procedures but are common compared to the overall number of spinal column and spinal nervous tissue surgeries. Surgical spinal (secondary) epidural neoplastic metastasis procedures were more common in this study relative to other spinal column and spinal nervous tissue tumours. Trend analysis indicates an unchanging trend of prevalence for spinal metastasis surgeries during the 19-year study period.

\section{Acknowledgements}

The authors extend their gratitude to the medical staff and residents of the Department of Surgery and the Division of Neurosurgery, Santa Casa de São Paulo-School of Medical Sciences, São Paulo, Brazil, for their collaboration and for making this manuscript possible.

\section{References}

[1] Araujo, J.L., Veiga, J.C., Figueiredo, E.G., Barboza, V.R., Daniel, J.W. and Panagopoulos, A.T. (2013) Management of Metastatic spinal Column Neoplasms-An Update. Revista do Colégio Brasileiro de Cirurgióes, 40, 508-513. http://dx.doi.org/10.1590/S0100-69912013000600015

[2] Byrne, T.N. (1992) Spinal Cord Compression from Epidural Metastases. The New England Journal of Medicine, 327, 614-619. http://dx.doi.org/10.1056/NEJM199208273270907

[3] Oliveira, M.F., Barros, B., de A., Rotta, J.M. and Botelho, R.V. (2013) Tokuhashi Scoring System Has Limited Applicability in the Majority of Patients with Spinal Cord Compression Secondary to Vertebral Metastasis. Arquivos de Neuro-Psiquiatria, 71, 798-801. http://dx.doi.org/10.1590/0004-282X20130125

[4] Quraishi, N.A., Gokaslan, Z.L. and Boriani, S. (2010) The Surgical Management of Metastatic Epidural Compression of the Spinal Cord. Journal of Bone and Joint Surgery-British, 92, 1054-1060. http://dx.doi.org/10.1302/0301-620X.92B8.22296

[5] Choi, D., Crockard, A., Bunger, C., Harms, J., Kawahara, N., Mazel, C., et al. (2010) Review of Metastatic Spine Tumour Classification and Indications for Surgery: The Consensus Statement of the Global Spine Tumour Study Group. European Spine Journal, 19, 215-222. http://dx.doi.org/10.1007/s00586-009-1252-x

[6] Mut, M., Schiff, D. and Shaffrey, M.E. (2005) Metastasis to Nervous System: Spinal Epidural 
and Intramedullary Metastases. Journal of Neuro-Oncology, 75, 43-56.

http://dx.doi.org/10.1007/s11060-004-8097-2

[7] Loblaw, D.A., Perry, J., Chambers, A. and Laperriere, N.J. (2005) Systematic Review of the Diagnosis and Management of Malignant Extradural Spinal Cord Compression: The Cancer Care Ontario Practice Guidelines Initiative's Neuro-Oncology Disease Site Group. Journal of Clinical Oncology, 23, 2028-2037. http://dx.doi.org/10.1200/JCO.2005.00.067

[8] National Cancer Institute. Cancer Staging. Bethesda, MD: National Institutes of Health (2015). https://www.cancer.gov/types/unknown-primary/hp

[9] Sciubba, D.M., Petteys, R.J., Dekutoski, M.B., Fisher, C.G., Fehlings, M.G., Ondra, S.L., et al. (2010) Diagnosis and Management of Metastatic Spine Disease. A Review. Journal of Neurosurgery: Spine, 13, 94-108. http://dx.doi.org/10.3171/2010.3.SPINE09202

[10] Daniel, J.W. and Veiga, J.C. (2014) Prognostic Parameters and Spinal Metastases: A Research Study. PLoS One, 9, Article ID: e109579.

http://dx.doi.org/10.1371/journal.pone.0109579

[11] Lau, D., Leach, M.R., La Marca, F. and Park, P. (2012) Independent Predictors of Survival and the Impact of Repeat Surgery in Patients Undergoing Surgical Treatment of Spinal Metastasis. Journal of Neurosurgery. Spine, 17, 565-576. http://dx.doi.org/10.3171/2012.8.SPINE12449

[12] Instituto Nacional de Câncer, Coordenação Geral de Ações Estratégicas. Estimate 2014: cancer incidence in Brazil, 2014. http://www.inca.gov.br/estimativa/2016/

[13] Estimate of the Resident Population in Brazil and Federal States Referenced to July 01, 2014.

ftp://ftp.ibge.gov.br/Estimativas_de_Populacao/Estimativas_2014/estimativas_2014_TCU.p df

[14] Bonita, R., Beaglehole, R. and Kjellström, T., Eds. (2006) Basic Epidemiology. 2nd Edition, World Health Organization, Geneva.

[15] National Cancer Institute (2015) Cancer Staging. National Institutes of Health Bethesda, MD. http://www.cancer.org/treatment/understandingyourdiagnosis/staging

[16] Perrin, R.G., Livingston, K.E. and Aarabi, B. (1982) Intradural Extramedullary Spinal Metastasis. A Report of 10 Cases. Journal of Neurosurgery, 56, 835-837. http://dx.doi.org/10.3171/jns.1982.56.6.0835

[17] Daniel, J.W. (2013) Survival Prognostic Parameters in Patients with Spinal Column Epidural Metastatic Neoplasms. Ph.D. Thesis, Santa Casa de São Paulo, Faculty of Medical Sciences, São Paulo.

http://www.fcmsantacasasp.edu.br/images/Pos-graduacao/dissertacoes-e-teses/Pesquisa-cir urgia/doutorado/2013-Jefferson-Walter-Daniel.pdf 
Submit or recommend next manuscript to SCIRP and we will provide best service for you:

Accepting pre-submission inquiries through Email, Facebook, LinkedIn, Twitter, etc. A wide selection of journals (inclusive of 9 subjects, more than 200 journals)

Providing 24-hour high-quality service

User-friendly online submission system

Fair and swift peer-review system

Efficient typesetting and proofreading procedure

Display of the result of downloads and visits, as well as the number of cited articles

Maximum dissemination of your research work

Submit your manuscript at: http://papersubmission.scirp.org/

Or contact ojepi@scirp.org 